\title{
MicroRNA 214 inhibits adipocyte enhancer-binding protein 1 activity and increases the sensitivity of chemotherapy in colorectal cancer
}

\author{
SHOUCHAO LI, CHENGREN LI and ZHIMING FANG \\ Department of Anorectal Surgery, Weifang People's Hospital, Weifang, Shandong 261000, P.R. China
}

Received October 13, 2016; Accepted January 10, 2018

DOI: $10.3892 / \mathrm{ol} .2018 .9623$

\begin{abstract}
The present study aimed to analyze adipocyte enhancer-binding protein 1 (AEBP1) expression in colorectal cancer (CRC), with a focus on its possible molecular mechanisms, in order to provide novel insight into the clinical treatment of CRC. Immunohistochemistry (IHC) was used to detect AEBP1 expression in 62 CRC tissues. Kaplan-Meier survival curves were used to analyze AEBP1 expression and the postoperative disease-free survival (DFS) and overall survival (OS) rates of CRC patients. HT-29 cells were treated with oxaliplatin to detect cell proliferation and apoptosis following a Cell Counting kit-8. Through bioinformatics prediction, microRNA 214 (miR214) was identified as an upstream microRNA of AEBP1 that regulates its expression. IHC revealed that the expression of AEBP1 in CRC tissues was significantly higher than that in adjacent healthy tissues, and that it is associated with Tumor-Node-Metastasis stage, recurrence and metastasis. The DFS and OS rates of patients with a low AEBP1 expression were significantly higher than those in patients with a high expression $(\mathrm{P}<0.05)$. Following depletion of AEBP1 and treatment with oxaliplatin, the HT-29 cell proliferation was lower than that of the blank control and the negative control groups. However, the cell apoptosis rate was higher than that of the control group at $72 \mathrm{~h}(\mathrm{P}<0.05)$. Bioinformatics prediction revealed that miR-214 is negatively associated with AEBP1 expression, and co-transfection and luciferase report gene tests revealed that AEBP1 is a target gene of miR-214. Therefore, AEBP1 may become a novel treatment for CRC patients with chemoresistance and may act through the upstream miR-214 to participate in the progression of a tumor.
\end{abstract}

Correspondence to: Dr Zhiming Fang, Department of Anorectal Surgery, Weifang People's Hospital, 151 Guangwen Street, Weifang, Shandong 261000, P.R. China

E-mail: 13780822899@163.com

Key words: microRNA 214, adipocyte enhancer-binding protein 1, chemotherapy, colorectal cancer, prognosis

\section{Introduction}

Colorectal cancer (CRC) is one of the most common malignant tumors with a high incidence worldwide (1). According to the International Agency for Research on Cancer (IARC) GLOBOCAN 2012 monitoring data, there were an estimated 1.36 million cases novel cases of CRC globally, and by 2017 the global novel cases of would rise to 3.54 million cases $(2,3)$. $\mathrm{CRC}$ has the third highest incidence among all malignant tumors, surpassed by only lung and breast cancer, and the fifth highest mortality rate worldwide (4). The incidence and mortality rates of CRC have declined in recent years in Western developed countries, but both parameters are steadily increasing in developing countries $(5,6)$. Due to the gradually changing eating habits and increased high fat and protein intake, the incidence of CRC in China is expected to become one of the fastest rising of all malignant tumors. The occurrence of $\mathrm{CRC}$ is associated with environmental and genetic factors (7). Typical monogenic disease accounts for only 1-5\% of CRC cases; the occurrence and development of CRC is a multi-step, multi-stage process, involving multiple genes, and events at the genome level and genetic polymorphisms form the basis of genetic susceptibility (8). Genetic research has primarily been focused on genes associated with cell cycle regulation, apoptosis, DNA repair and metabolism.

Adipocyte enhancer-binding protein 1 (AEBP1) is a newly identified type of inflammation-associated regulatory factor (9) and a previous study demonstrated that AEBP1 may inhibit the $\kappa \mathrm{B}$ inhibitor, $\mathrm{I} \kappa \mathrm{B} \alpha$, in order to promote the activity of the nuclear factor (NF) $-\kappa B$ pathway, which is involved in a number of biological functions (10). Additionally, evidence suggests that AEBP1 is likely to be involved in the occurrence of numerous tumors $(11,12)$. Further study of the key molecular mechanisms of AEBP1 for novel drug development and clinical treatment has important social value and clinical significance. At present, studies regarding AEBP1 expression in CRC cells and the use of oxaliplatin in chemotherapy sensitivity are insufficient.

In the present study, CRC tissues were used to detect the associations among AEBP1 expression, patient survival and tumor pathology in $\mathrm{CRC}$, in order to investigate chemotherapy sensitivity in HT-29 cells following AEBP1 depletion, and to study the role of AEBP1 in the biological functions of CRC, including infiltration, differentiation and metastasis. AEBP1 is 
expected to become a predictor of recurrent CRC metastasis and is a potential molecular target for treatment.

\section{Patients and methods}

Patient tissue samples. A total of 62 randomly selected patients at Weifang People's Hospital (Weifang, China) underwent CRC tumor resection between January 2010 and December 2012. Follow-up, ranging between 4 and 63 months (median, 35 months), was available for all 62 patients. Of the group, 42 patients were male and 20 were female with ages ranging between 28 and 79 years (median, 66 years). The clinical features of the patients are presented in Table I. The records of all of the patients contained basic information, including Tumor-Node-Metastasis (TNM) stage, the degree of differentiation, lymph node metastasis and distant metastasis, according to the 2002 International Cancer Alliance TNM staging criteria (13). Paired non-cancerous tissues were obtained from a segment of the resected specimens that was $>5 \mathrm{~cm}$ from the tumor. All the tissue specimens were placed in liquid nitrogen or were fixed with $4 \%$ formaldehyde for $24 \mathrm{~h}$ at room temperature (RT) within half an hour of the tumor resection. The present clinical study was approved by the Medical Ethics Committee of Weifang People's Hospital and written informed consent was obtained from all patients upon admission.

Immunohistochemistry (IHC) and result interpretation. AEBP1 expression was analyzed by IHC on paraffin-embedded tissue specimens from the 62 patients with CRC. The excised tumor samples were fixed with $4 \%$ formaldehyde for 18-24 $\mathrm{h}$ at RT and embedded in paraffin prior to being prepared into consecutive $5-\mu \mathrm{m}$ sections. The sections were dewaxed with xylene then hydrated through a graded series of ethanol (70, 80, 90, 95 and $100 \%)$ for 5 min of each series at RT. Following general deparaffinization, antigen retrieval was performed at $95^{\circ} \mathrm{C}$ for $30 \mathrm{sec}$ with an autoclave using $0.01 \mathrm{~mol} / \mathrm{l}$ sodium citrate buffer $(\mathrm{pH}$ 6.0). Hydrogen peroxide $(0.3 \%)$ was used to block endogenous peroxidase activity for $30 \mathrm{~min}$ at $37^{\circ} \mathrm{C}$, and non-specific immunoglobulin binding sites were blocked using 5\% normal goat serum (cat. no. SP KIT-B1; Fuzhou Maixin Biotech Co., Ltd.) for $30 \mathrm{~min}$ at $37^{\circ} \mathrm{C}$. The sections were incubated at $4^{\circ} \mathrm{C}$ overnight with a purified AEBP1 rabbit polyclonal antibody (Novus Biologicals, LLC, Littleton, CO, USA; dilution, 1:200). The sections were rinsed 3 times with phosphate-buffered saline (PBS) for 5 min each time prior to being incubated for $30 \mathrm{~min}$ at RT with a biotinylated anti-mouse/rabbit IgG secondary antibody [dilution, 1:100; cat. no. KIT-0305; UltraSensitive ${ }^{\mathrm{TM}}$ SP (Mouse/Rabbit) IHC Kit, Fuzhou Maixin Biotech Co., Ltd.]. Following washing, the sections were incubated for $30 \mathrm{~min}$ at RT with streptavidin-biotin conjugated with horseradish peroxidase [dilution, 1:100; cat. no. KIT-0305; UltraSensitive ${ }^{\mathrm{TM}}$ SP (Mouse/Rabbit) IHC kit], and the slides were visualized with 3,3'-diaminobenzidine tetrahydrochloride. The sections were stained with Meyer's hematoxylin for 2 min at RT. As a negative control, normal rabbit IgG (cat. no. A7016) or mouse IgG (cat. no. A7028; both dilution, 1:100; both Beyotime Institute of Biotechnology, Haimen, China) was used as the primary antibody and incubated for $30 \mathrm{~min}$ at RT.
The staining intensity score was defined as 0 points (negative), 1 point (weakly positive), 2 points (positive) and 3 points (strongly positive). Percent positivity scores were defined as follows: 1 ( $<25 \%$ cell staining), 2 ( $25-50 \%$ cell staining), $3(51-75 \%)$ and 4 ( $>75 \%$ of cells staining). The final score was defined as the value of the percent positivity score multiplied by the staining intensity score and final scores ranged between 0 and 12. The tumors were divided as follows: Negative (-), score 0 ; low expression (1+), score 1-4; moderate expression (2+), score 5-8; and strong expression (3+), score 9-12. The IHC results of AEBP1 were grouped into 2 categories: Low expression (0 and $1+)$ and high expression (2+ and $3+)$.

Cell transfection and cell proliferation/apoptosis detection. The human CRC HT29 cell line was purchased from the Cell Bank of Type Culture Collection of Chinese Academy of Sciences (Shanghai, China). The cells were cultured in RPMI-1640 medium containing 10\% fetal bovine serum (FBS) (both Gibco; Thermo Fisher Scientific, Inc., Waltham, MA, USA). The cells were cultured at $37^{\circ} \mathrm{C}$ in a $5 \% \mathrm{CO}_{2}$ incubator and used in subsequent experiments when they had grown in cell culture flask to $80-100 \%$ confluence. AEBP1 depletion siRNA (Shanghai GenePharma Co., Ltd, Shanghai, China) was transfected into cells in 6-well plates for $36 \mathrm{~h}$ of cell culture until the cells reached $70-80 \%$ confluence. The AEBP1 sequences used were as follows: Forward, 5'-CAT CTACCCACTCACCTGGAA-3' and reverse, 5'-CACTCC TCGTTCACCACCTT-3'. A microRNA 214 (miR-214) mimic (transfected with $1 \mu \mathrm{g} / 100 \mu \mathrm{l}$ miR-214 mimic; Nanjing KeyGen BioTech Co., Ltd, Nanjing, China), negative-scramble control (transfected with negative mimic, NC) and blank control (non-transfected cells, BC) were used for transfection. The miR-214 sequences were as follows: Forward, 5'-AGC ATAATACAGCAGGCACAGAC-3 and reverse, 5'-AAA GGTTGTTCTCCACTCTCTCAC-3'. The transfections were performed using Lipofectamine 2000 (Invitrogen; Thermo Fisher Scientific, Inc.). To begin with, solution A [10 $\mu$ 1 $100 \mathrm{pmol} / \mu \mathrm{l}$ AEBP1 siRNA $+250 \mu \mathrm{l}$ opti-minimum essential medium (MEM; Gibco; Thermo Fisher Scientific, Inc.)] and solution B (10 $\mu \mathrm{l}$ Lipofectamine $2000+250 \mu 1$ opti-MEM) were prepared. The 2 solutions $(\mathrm{A}+\mathrm{B})$ were then mixed together and incubated for $20 \mathrm{~min}$ at RT. Next, $500 \mu \mathrm{l} \mathrm{A}+\mathrm{B}$ and $1.5 \mathrm{ml}$ opti-MEM were added dropwise into each well of the 6-well plate. The transfected cells were cultured at $37^{\circ} \mathrm{C}$ for $6 \mathrm{~h}$, the medium was removed, and then $2 \mathrm{ml} \mathrm{RPMI-1640}$ medium with $10 \%$ FBS (both Gibco; Thermo Fisher Scientific, Inc.) was added, followed by incubation for $36 \mathrm{~h}$ prior to further experiments. Each group was set up in 3 replicate wells.

HT29 cells $\left(2 \times 10^{3}\right)$ were plated into each well of a 96-well plate and were subsequently transfected with AEBP1 depletion siRNA, a negative scramble control and a BC. Following cell transfection, $50 \mu \mathrm{g} / \mathrm{ml}$ oxaliplatin was added to the plate at $6,12,24,36,48,60$ and $72 \mathrm{~h}$ prior to the addition of the CCK- 8 reagent at $37^{\circ} \mathrm{C}$. (Nanjing KeyGen Biotech Co., Ltd., Nanjing, China). The optical density value was detected at a wavelength of $450 \mathrm{~nm}$. Each group was set up in 5 replicate wells.

Suspended cells $\left(2 \times 10^{4}\right)$ were plated into each well of 6-well plates (with a coverslip) for transfection. The cells were then treated with oxaliplatin (added dropwise, $100 \mu \mathrm{g} / 2 \mathrm{ml}$ ) for $72 \mathrm{~h}$ 
Table I. Association between AEBP1 distribution and clinicopathological characteristics in colorectal cancer patients.

\begin{tabular}{|c|c|c|c|c|c|}
\hline \multirow[b]{2}{*}{ Variable } & \multirow[b]{2}{*}{ Number } & \multicolumn{3}{|c|}{ AEBP1 } & \multirow[b]{2}{*}{ P-value } \\
\hline & & High & Low & $\chi^{2}$ & \\
\hline Total cases & 62 & 39 & 23 & & \\
\hline Age, years & & & & 1.986 & 0.159 \\
\hline$\geq 60$ & 36 & 20 & 16 & & \\
\hline$<60$ & 26 & 19 & 7 & & \\
\hline Sex & & & & 0.353 & 0.553 \\
\hline Male & 30 & 20 & 10 & & \\
\hline Female & 32 & 19 & 13 & & \\
\hline Tumor size, cm & & & & 1.728 & 0.189 \\
\hline$\geq 5$ & 31 & 22 & 9 & & \\
\hline$<5$ & 31 & 17 & 14 & & \\
\hline TNM stage & & & & 5.939 & 0.015 \\
\hline $\mathrm{I}+\mathrm{II}$ & 28 & 13 & 15 & & \\
\hline III+IV & 34 & 26 & 8 & & \\
\hline Tumor differentiation & & & & 2.375 & 0.305 \\
\hline WD & 20 & 10 & 10 & & \\
\hline MD & 20 & 13 & 7 & & \\
\hline $\mathrm{PD}$ & 22 & 16 & 6 & & \\
\hline Recurrence & & & & 7.281 & 0.007 \\
\hline Yes & 30 & 24 & 6 & & \\
\hline No & 32 & 15 & 17 & & \\
\hline Metastasis & & & & 8.793 & 0.003 \\
\hline Yes & 34 & 27 & 7 & & \\
\hline No & 28 & 12 & 16 & & \\
\hline
\end{tabular}

AEBP1, adipocyte enhancer-binding protein 1; TNM, tumor-node-metastasis; AEBP1, adipocyte enhancer-binding protein 1; WD, well-differentiated; MD, moderately-differentiated; PD, poorly differentiated.

and a FITC Annexin V-PI apoptosis detection kit (Nanjing KeyGen Biotech Co., Ltd.) was performed. Cells were collected by trypsin (without ethylenediamime-N,N,N'N'-tetraacetic acid) digestion. Following washing and centrifuging at $700 \mathrm{x} g$ for $5 \mathrm{~min}$ at $4^{\circ} \mathrm{C}, 5 \times 10^{5}$ cells were suspended in $500 \mu \mathrm{l}$ binding buffer (Nanjing KeyGen Biotech Co., Ltd.), and incubated for 15 min with $5 \mu \mathrm{l}$ Annexin V-fluorescein isothiocyanate and $5 \mu \mathrm{l}$ propidium iodide for $10 \mathrm{~min}$ at $\mathrm{RT}$ in the dark. The cells were quantitatively analyzed by a standard Becton-Dickinson FACSAria instrument (BD FACSAria ${ }^{\mathrm{TM}} \mathrm{III}$; BD Biosciences, Franklin Lakes, NJ, USA). The data was acquired and analyzed using the FACS DiVa 4.1 software (BD Biosciences).

AEBP1 upstream target gene prediction and dual-luciferase assay. Targetscan (http://www.targetscan.org/), Pictar (http://pictar.mdc-berlin.de/) and miRanda (http://www. microrna.org/microrna/home.do) were used topredictupstream miRNA target genes. Through bioinformatics prediction from the three aforementioned websets, the AEBP1 3'-untranslated region (UTR) was revealed to be associated with an miR-214 binding site and thus, wild-type (WT) and mutant (MUT) AEBP1 3'-UTR luciferase reporter gene plasmids (Luc-AEBP-3'-UTR; Shanghai GenePharma Co., Ltd.) were constructed for further study. Luc-AEBP-3'-UTR (WT) or (MUT) 3'-pGL3 luciferase reporter vectors were constructed by Shanghai GeneChem Co., Ltd. (Shanghai, China). 293T cells were plated onto 96 -well plates at $60 \%$ confluence $24 \mathrm{~h}$ prior to transfection. According to Lipofectamine ${ }^{\circledR}$ 2000 Transfection Reagent Instructions (Invitrogen; Thermo Fisher Scientific, Inc.) for transfection operation. At the time of transfection, $50 \mu 1$ RPMI-1640 medium, $50 \mu 1$ Dual Glo ${ }^{\circledR}$ Luciferase reagent (premix; Promega Corporation, Madison, WI, USA), and $100 \mu 1 \mathrm{Glo}^{\circledR}$ Stop and Glo ${ }^{\circledR}$ reagent (Promega Corporation) were added to each well of a LockWell MaxiSorp test plate (Thermo Fisher Scientific, Inc., Waltham, MA, USA). The Firefly and Renilla luciferase fluorescence values (Renilla luciferase activity as a reference for transfection efficiency) were detected using a Dual-Luciferase ${ }^{\circledR}$ Reporter Assay System (Promega Corporation). The experiment was repeated 3 times.

Western blot analysis. Total HT-29 cell protein was extracted in lysis buffer (Pierce; Thermo Fisher Scientific, Inc.) and quantified using the Bradford method (14). AEBP1 was detected. Protein $(50 \mu \mathrm{g})$ was separated using $12 \%$ SDS-PAGE electrophoresis. After the proteins were transferred to polyvinylidene 
Table II. Univariate survival analyses of individual parameters and associations with OS and DFS using the Cox proportional hazards model.

\begin{tabular}{|c|c|c|c|c|c|c|}
\hline \multirow[b]{2}{*}{ Variable } & \multicolumn{3}{|c|}{ OS } & \multicolumn{3}{|c|}{ DFS } \\
\hline & HR & $95 \%$ CI & P-value & HR & $95 \%$ CI & P-value \\
\hline AEBP1 expression & 1.994 & $1.322-2.839$ & $0.006^{\mathrm{a}}$ & 1.661 & $1.178-2.341$ & $0.004^{\mathrm{a}}$ \\
\hline Age & 1.211 & $0.476-1.118$ & 0.473 & 1.321 & $0.544-1.008$ & 0.532 \\
\hline Sex & 1.107 & $0.797-1.543$ & 0.633 & 1.009 & $0.808-1.431$ & 0.562 \\
\hline TNM stage & 1.865 & $1.315-2.865$ & $0.004^{\mathrm{a}}$ & 1.930 & $1.455-2.744$ & $0.003^{\mathrm{a}}$ \\
\hline Tumor size & 1.205 & $0.901-1.578$ & 0.173 & 1.327 & $0.879-1.666$ & 0.099 \\
\hline Tumor differentiation & 1.110 & $0.821-1.581$ & 0.544 & 1.132 & $0.769-1.415$ & 0.650 \\
\hline Recurrence & 1.644 & $1.202-2.887$ & $0.017^{\mathrm{a}}$ & 1.600 & $1.173-2.591$ & $0.011^{\mathrm{a}}$ \\
\hline Metastasis & 1.555 & $1.039-2.303$ & $0.020^{\mathrm{a}}$ & 1.471 & $1.119-2.552$ & $0.014^{\mathrm{a}}$ \\
\hline
\end{tabular}

${ }^{\mathrm{a}} \mathrm{P}<0.05$. AEBP1, adipocyte enhancer-binding protein 1; HR, hazard ratio; CI, confidence interval; OS, overall survival; DFS, disease-free survival; TNM, Tumor-Node-Metastasis.

fluoride membranes (EMD Millipore, Billerica, MA, USA), and the membranes were blocked with $5 \%$ skimmed milk in Tris-buffered saline with $0.1 \%$ Tween-20 at RT for $2 \mathrm{~h}$; following this, the membranes were incubated overnight at $4^{\circ} \mathrm{C}$ with antibodies against AEBP1 (cat. no. sc-271374; 1:500), or $\beta$-actin (cat. no. sc-47778; 1:2,000; both Santa Cruz Biotechnology, Inc., Dallas, TX, USA). Following washing with TBS with Tween-20 three times, the membranes were incubated with rabbit anti-mouse IgG-HRP (cat. no. ab6728; 1:5,000; Abcam, Cambridge, MA, USA) for $2 \mathrm{~h}$ at RT. The enhanced chemiluminescence chromogenic system (EMD Millipore) was used prior to imaging, and the experiment was repeated in triplicate.

Statistical analysis. SPSS 17.0 (SPSS, Inc., Chicago, IL, USA) for Windows was used for all statistical analyses. The $\chi^{2}$ test was used to evaluate the associations between AEBP1 expression and various clinicopathological parameters. The differences between the means of the two groups were determined by one-way analysis of variance (ANOVA) with post-hoc Dunnett's comparison. The Kaplan-Meier method was used to estimate patient survival rates and these results were compared using the log-rank test. Cox regression was performed for univariate and multivariate analysis of prognostic variables. $\mathrm{P}<0.05$ was considered to indicate a statistically significant difference.

\section{Results}

AEBPI-positive expression and the association between $A E B P 1$ and CRC clinicopathological parameters. AEBP1 protein expression in the CRC tissues and their paired non-cancerous tissues from the 62 patients were examined by IHC and AEBP1 was primarily expressed in the nucleus and the cytoplasm (Fig. 1), with a high expression in 39/62 of the CRC samples. There was no expression in normal colonic mucosal tissues. The $\chi^{2}$ test results confirmed that there was a significant positive association between AEBP1 protein expression and the presence of lymph node metastasis

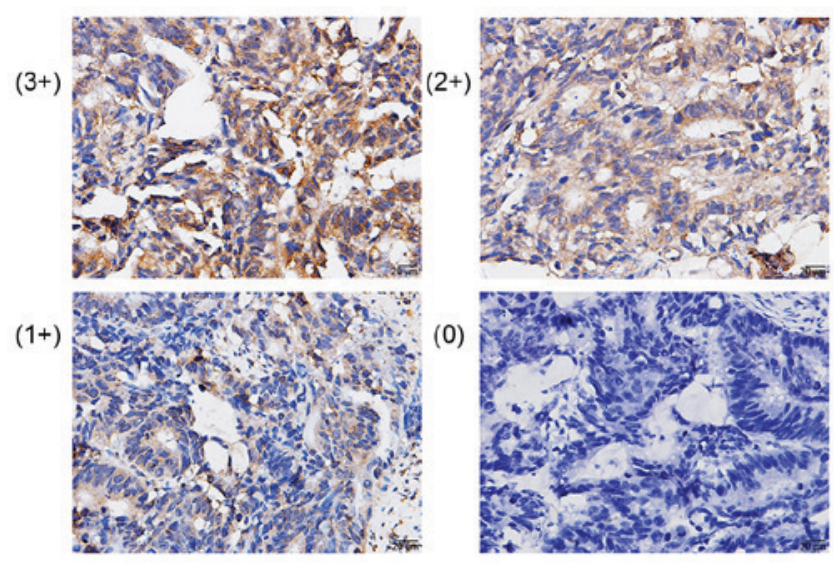

Figure 1. Immunohistochemistry of colorectal cancer tissues and adjacent non-cancerous tissues. Representative tissue sections with different immunointensities of adipocyte enhancer-binding protein 1 . Histological type: $3+$, strong expression; $2+$, moderate expression; $1+$, weak expression; 0 , negative expression. Magnification, $\mathrm{x} 400$.

$(\mathrm{P}=0.003)$, with a positive expression rate of $54.8 \%(34 / 62$; $\left.\chi^{2}=8.793\right)$. The AEBP1 protein level was also significantly associated with TNM staging. The AEBP1-positive expression rate at tumor stages III and IV was 76.5\% (26/34), significantly higher than that at stages I and II at 46.4\% $\left(13 / 28 ; \chi^{2}=5.939\right.$; $\mathrm{P}=0.015)$. The AEBP1-positive expression rate was $80.0 \%$ $(24 / 30)$ in the recurrence group, significantly higher than that in the non-metastasis group at $46.9 \%(15 / 32)\left(\chi^{2}=7.281\right.$; $\mathrm{P}=0.007)$. However, no association was observed between AEBP1 protein expression and age or sex (Table I).

Impact of AEBP1 expression on overall survival (OS) and $(D F S)$ in $C R C$. Upon univariate analysis, age, sex, tumor size and histopathological differentiation were not predictive values for OS or DFS (Table II; P>0.05). However, AEBP1 expression, TNM stage, metastasis and recurrence were revealed to be independent prognostic factors for OS and DFS. (Table II; $\mathrm{P}<0.05$ ). Multivariate analysis of the aforementioned prognostic parameters also revealed that AEBP1 expression 
Table III. Multivariate survival analysis of individual parameters and associations with OS and DFS using the Cox proportional hazards model.

\begin{tabular}{|c|c|c|c|c|c|c|}
\hline \multirow[b]{2}{*}{ Variable } & \multicolumn{3}{|c|}{ OS } & \multicolumn{3}{|c|}{ DFS } \\
\hline & HR & $95 \%$ CI & P-value & HR & $95 \% \mathrm{CI}$ & P-value \\
\hline AEBP1 expression & 1.675 & $1.142-2.242$ & $0.008^{\mathrm{a}}$ & 1.611 & $1.143-2.333$ & $0.006^{\mathrm{a}}$ \\
\hline TNM stage & 1.654 & $1.153-2.737$ & $0.007^{\mathrm{a}}$ & 1.720 & $1.211-2.554$ & $0.009^{\mathrm{a}}$ \\
\hline Recurrence & 1.426 & $1.104-2.665$ & $0.021^{\mathrm{a}}$ & 1.459 & $1.060-2.408$ & $0.020^{\mathrm{a}}$ \\
\hline Metastasis & 1.344 & $1.102-2.208$ & $0.028^{\mathrm{a}}$ & 1.394 & $1.110-2.446$ & $0.023^{\mathrm{a}}$ \\
\hline
\end{tabular}

${ }^{\mathrm{a}}<<0.05$. AEBP1, adipocyte enhancer-binding protein 1; HR, hazard ratio; CI, confidence interval; OS, overall survival; DFS, disease-free survival; TNM, Tumor-Node-Metastasis.
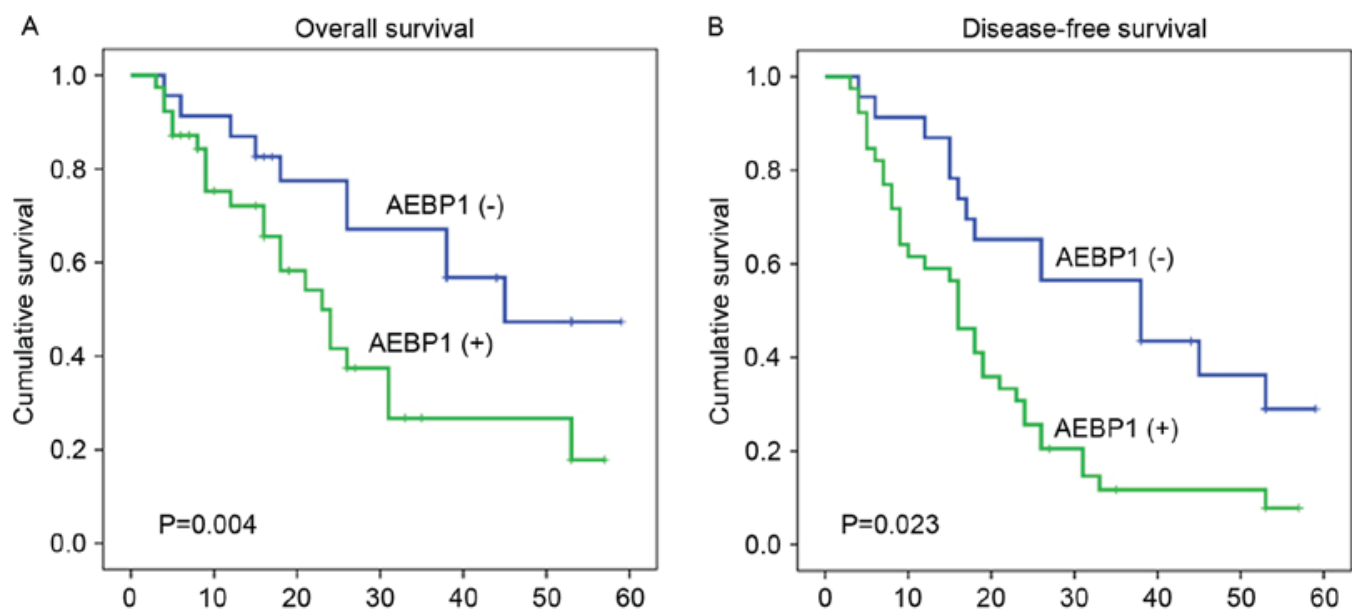

Figure 2. Kaplan-Meier survival analysis of primary colorectal cancer patients $(n=62)$ following surgical resection with high AEBP1 expression ( $\mathrm{n}=39)$ and low AEBP1 expression (n=23). (A) OS following surgery and (B) DFS following surgery. AEBP1, adipocyte enhancer-binding protein 1; OS, overall survival; DFS, disease-free survival.

(HR, 1.675; 95\% CI, 1.142-2.242; $\mathrm{P}=0.008$ ), TNM stage, metastasis and recurrence were independent prognostic indicators for the OS of patients with CRC (Table II; $\mathrm{P}<0.05$ ). Additionally, AEBP1 expression (HR, 1.611; 95\% CI, 1.143-2.333; $\mathrm{P}=0.006$ ), TNM stage, metastasis and recurrence were independent prognostic indicators for DFS in patients with CRC (Table III; P<0.05). Using the Kaplan-Meier method and the log-rank test, CRC samples with a higher expression of AEBP1 were revealed to have a shorter OS or DFS (Fig. 2A and B; log-rank values, 8.286 and 5.177, respectively; $\mathrm{P}=0.004$ and $\mathrm{P}=0.023$, respectively).

Effects of AEBP1 depletion combined with oxaliplatin treatment on cell proliferation and apoptosis of HT-29 cells. Apoptosis detection revealed that the apoptosis rate of the experimental group was significantly higher, compared with the negative control and $\mathrm{BC}$ group (Fig. $3 \mathrm{~A} ; \mathrm{P}<0.05$ ), and no statistically significant differences were observed between the two control groups $(\mathrm{P}>0.05)$. Following cell transfection and oxaliplatin treatment, the cell proliferation in the experimental group at 5 time points was determined. The absorbance values of the experimental group were significantly lower, compared with the other two groups, as measured by the CCK- 8 assay (Fig. 3B; $\mathrm{P}<0.01$ ). While no significant difference was observed between the 2 control groups $(\mathrm{P}>0.05)$, indicating that inhibiting AEBP1 expression in HT-29 cells under the effect of chemotherapy drugs may inhibit cell proliferation ability.

The miR-214 mimic and pMIR-REPORT luciferase vectors containing the AEBP1 3'-UTR binding site fragment were co-transfected. Compared with the negative or blank co-transfection group, the enzyme activity decreased by $30 \%$ in the mimic co-transfection group, demonstrating that AEBP1 is the target of miR-214 (Fig. 3C). AEBP1 was identified as the main downstream target of miR-214. Following transfection of the miR-214 mimic into the HT-29 cells, AEBP1 expression was significantly lower than that of the negative control group $(\mathrm{P}<0.01$, blank control group gray value is set to 1$)$. No significant differences were detected between the negative control and the BC group (Fig. 3D; P>0.05).

\section{Discussion}

At present, CRC is one of the most common types of malignant tumor in humans but its pathogenic mechanisms remain unclear. Additionally, chronic inflammation often destroys the normal connection between epithelial and stromal cells, thereby inducing tumor development (15). Previous studies have demonstrated that AEBP1 is an important regulatory 

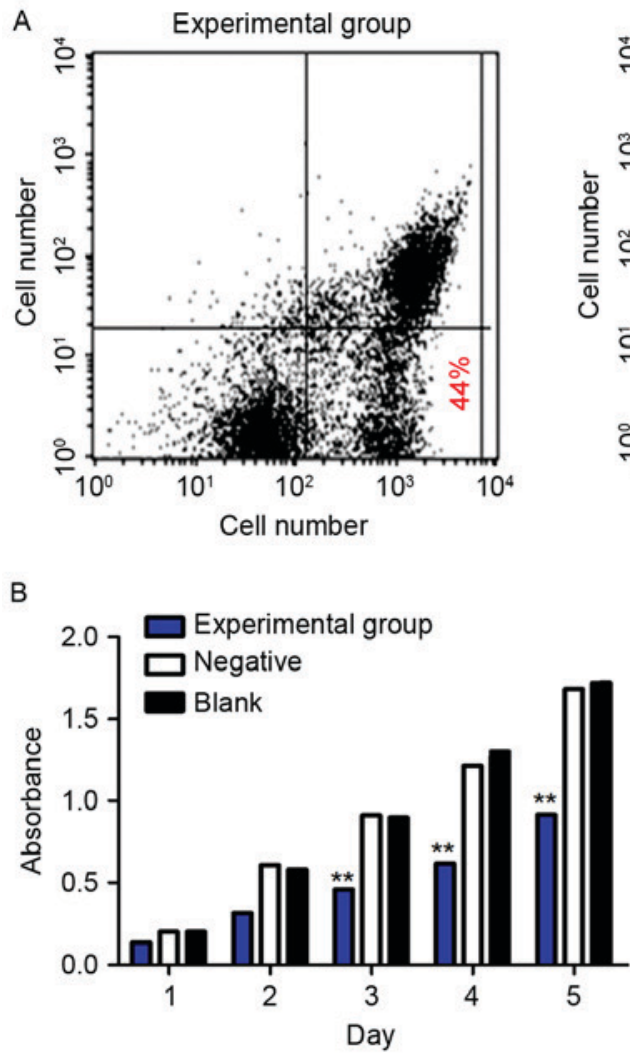

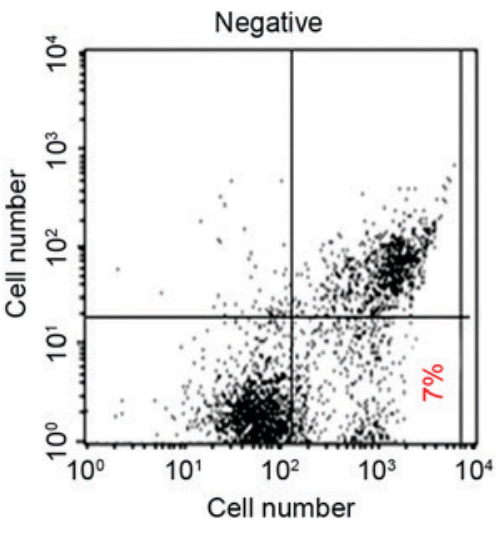

C

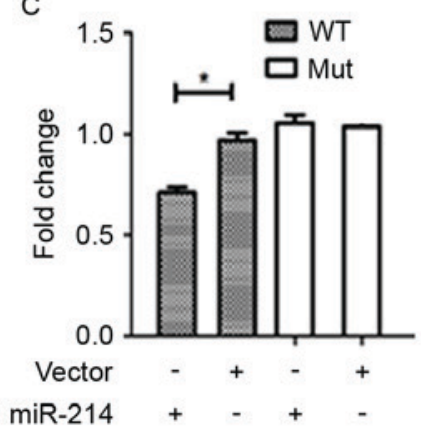

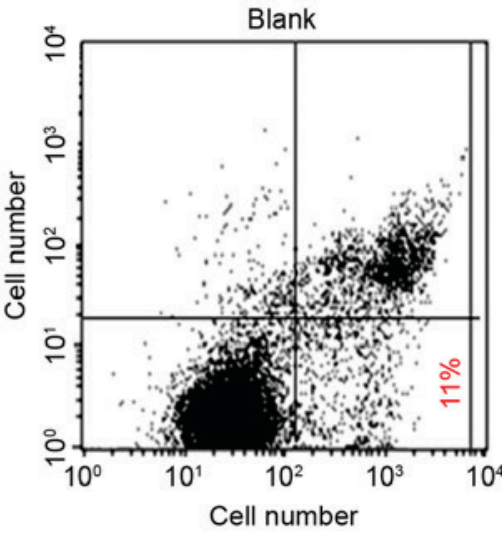

D

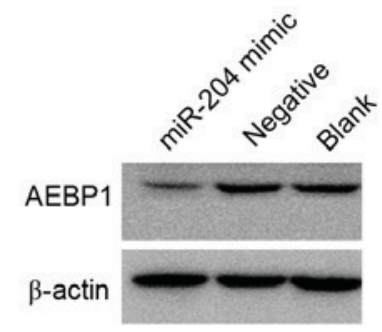

Figure 3. (A) Cell proliferation detection in groups using the Cell Counting kit-8 method and apoptosis detection. (B) Cell apoptosis ratio in HT-29 cells following cell transfection and oxaliplatin treatment. Experimental group absorbance optical density values are significantly lower than those of the other 2 groups $\left({ }^{* *} \mathrm{P}<0.05\right)$. No statistically significant differences were observed between the negative and the blank control groups. (C) Relative luciferase activity analyses. The relative luciferase activity of the vector (+) group was set as 1 (compared with WT miR-214, ${ }^{*} \mathrm{P}<0.05$ ). (D) HT-29 cell lysates were obtained for western blot analysis of AEBP1 following transfection. $\beta$-actin served as a control. WT, wild type; Mut, mutant; miR-214, microRNA-214; AEBP1, adipocyte enhancer-binding protein 1.

factor in inflammation, serving a key function in the pathogenesis of atherosclerosis, and have proven its use as a target of the prevention and treatment of atherosclerosis $(16,17)$. In rat prostate cancer cell lines, AEBP1 has been demonstrated to function as a transcription-inhibiting factor with carboxypeptidase activity, and has been reported to be methylated and to participate in the regulation of mitogen-activated protein kinase activity (18). In PLX4032-resistant melanoma cells, Hu et al (11) reported that AEBP1 was demonstrated to be highly upregulated because of the hyperactivation of the PI3K/Akt-cAMP response element-binding protein signaling pathway, which resulted in NF- $\kappa B$ pathway activation. These results demonstrated that AEBP1 may be a novel genetic therapy target for BRAF inhibitor-resistant melanoma [AEBP1 upregulation confers acquired resistance to BRAF (V600E) inhibition in melanoma]. Holloway et al (17) demonstrated that AEBP1, implicated as a novel pro-inflammatory mediator, has an effect on tumor cell growth and survival through aberrant sonic hedgehog expression and that it regulates the cross-talk between the mammary epithelium and stroma that may predispose the mammary tissue to tumorigenesis (17).

To date, there has been no systematic study on AEBP1 expression in CRC and the results of the present study are the first to demonstrate that the AEBP1 protein is involved in the development of CRC. AEBP1 expression is strongly associated with clinical stage, lymph node metastasis and recurrence. High expression of AEBP1 leads to a poor prognosis and is an independent risk factor for CRC prognosis. Therefore, AEBP1 expression may be used to monitor disease progression in patients with CRC tumor markers.

The primary auxiliary treatment of advanced-stage CRC is chemotherapy. Adjuvant chemotherapy following surgery may prolong the DFS and OS time and improve patient quality of life (19). However, clinical chemoresistance in tumor cells is the leading cause of treatment failure (20). Therefore, investigation into the cellular mechanisms underlying tumor chemoresistance has clinical significance. The present study revealed that, in HT-29 cells, the inhibition of AEBP1 expression combined with oxaliplatin treatment resulted in significantly lower cell proliferation and markedly increased apoptosis, indicating that the expression of AEBP1 has an effect on the sensitivity of tumor cells to chemotherapy. Previously, it was demonstrated that Bim, a B-cell lymphoma 2 family member, is an important apoptosis regulating protein; that Myc and E2F transcription factors regulate cell proliferation and apoptosis, and that their expression at the cellular level determines whether they function as oncogenes or tumor suppressor genes involved in tumorigenesis (21). Downregulated phosphatase and tensin homolog (PTEN) protein expression and the Akt pathway hyperactivation resulting from the PTEN downregulation may lead to cisplatin resistance in gastric cancer (22). Valeri et al (23) observed that miR-21 downregulated hMSH2 protein expression in CRC, leading to fluorouracil resistance. Mishra et al (24) revealed that miR-24 binding sites, including 
single-nucleotide mutations, cause cells to develop resistance to methotrexate, and that miR-221 inhibited the expression of p27kip1, which mediates tumor cells to develop drug resistance. In CRC, AEBP1 affects the specific function of HT-29 chemoresistance, but the associated mechanisms require further investigation.

The present study demonstrates that, through AEBP1 upstream target gene prediction, miR-214 may negatively regulate the expression of AEBP1 in CRC. miR-214 is an important miRNA molecule, and a number of previous studies have demonstrated that miR-214 is expressed at varying levels in human malignant tumors and that it affects the progression of the tumor and chemoresistance through different target genes and molecular mechanisms. Qiang et al (25) demonstrated that miR-214 expression in cervical cancer tissues is significantly lower than that in normal cervical tissues. The expression of miR-214 is negatively associated with the invasive ability of the tumor and patient clinical outcomes, and miR-214 may inhibit the expression of the target gene plexin-B1 to inhibit the proliferation of HeLa cells (25). Yang et al (26) also demonstrated that miR-214 was expressed at a lower level in cervical cancer tissues than in normal cervical tissues and may negatively regulate the target genes MEK3 and JNK1 to inhibit cell proliferation in cervical cancer HeLa cells.

In conclusion, the present study revealed that miR-214 may serve as the upstream gene involved in AEBP1 regulation, most likely by negatively regulating AEBP1 to enhance the sensitivity of HT-29 cells to oxaliplatin chemotherapy.

\section{Acknowledgements}

Not applicable.

\section{Funding}

No funding was received.

\section{Availability of data and materials}

All data generated or analyzed during this study are included in this published article.

\section{Authors' contributions}

SL conceived the study and wrote the manuscript. CL performed the experiments. ZF assisted in collecting and analyzing the patient data regarding the clinicopathological parameters of colorectal cancer. All authors read and approved the final manuscript.

\section{Ethics approval and consent to participate}

The study was approved by the ethics committee of Weifang People's Hospital and informed consent to participate was signed by the patients.

\section{Patient consent for publication}

Written informed consent was obtained from all participants for the publication of any data/associated images.

\section{Competing interests}

The authors declare that they have no competing interests.

\section{References}

1. Fukushima K, Tsuchiya K, Kano Y, Horita N, Hibiya S, Hayashi R, Kitagaki K, Negi M, Itoh E, Akashi T, et al: Atonal homolog 1 protein stabilized by tumor necrosis factor $\alpha$ induces high malignant potential in colon cancer cell line. Cancer Sci 106: 1000-1007, 2015.

2. International Agency for Research on Cancer: Estimated incidence, mortality and 5-year prevalence: Both sexes [EB/OL]. http://globocan.iarc.fr/Pages/fact_sheets_population.aspx, 2017

3. National cancer institute: SEER stat fact sheets: Colon and rectum cancer [EB/OL]. http://seer.cancer.gov/statfacts/html/colorect. html, 2017

4. Andersen HS, Bertelsen CA, Henriksen R, Campos AH, Kristensen B, Ingeholm $\mathrm{P}$ and Gögenur I: The pathological phenotype of colon cancer with microsatellite instability. Dan Med J 63: pii: A5198, 2016.

5. van de Velde CJ, Aristei C, Boelens PG, Beets-Tan RG, Blomqvist L, Borras JM, van den Broek CB, Brown G, Coebergh JW, Cutsem EV, et al: EURECCA colorectal: Multidisciplinary mission statement on better care for patients with colon and rectal cancer in Europe. Eur J Cancer 49: 2784-2790, 2013

6. Ku G, Tan IB, Yau T, Boku N, Laohavinij S, Cheng AL, Kang YK and de Lima Lopes G Jr: Management of colon cancer: Resource-stratified guidelines from the Asian oncology summit 2012. Lancet Oncol 13: e470-e481, 2012.

7. Guan X, Chen W, Liu Z, Jiang Z, Hu H, Zhao Z, Wang S, Chen Y, Wang $\mathrm{G}$ and Wang $\mathrm{X}$ : Whether regional lymph nodes evaluation should be equally required for both right and left colon cancer. Oncotarget 7: 59945-59956, 2016.

8. Huang B, Feng Y, Zhu L, Xu T, Huang L and Cai G: Smaller tumor size is associated with poor survival in stage II colon cancer: An analysis of 7,719 patients in the SEER database. Int J Surg 33 Pt A: 157-163, 2016.

9. Bogachev O, Majdalawieh A, Pan X, Zhang L and Ro HS: Adipocyte enhancer-binding protein 1 (AEBP1) (a novel macrophage proinflammatory mediator) overexpression promotes and ablation attenuates atherosclerosis in ApoE (-/-) and LDLR (-/-) mice. Mol Med 17: 1056-1064, 2011.

10. Majdalawieh A and Ro HS: Regulation of IkappaBalpha function and NF-kappaB signaling: AEBP1 is a novel proinflammatory mediator in macrophages. Mediators Inflamm 2010: 823821, 2010.

11. Hu W, Jin L, Jiang CC, Long GV, Scolyer RA, Wu Q, Zhang XD, Mei Y and Wu M: AEBP1 upregulation confers acquired resistance to BRAF (V600E) inhibition in melanoma. Cell Death Dis 4: e914, 2013.

12. Ladha J, Sinha S, Bhat V, Donakonda S and Rao SM: Identification of genomic targets of transcription factor AEBP1 and its role in survival of glioma cells. Mol Cancer Res 10: 1039-1051, 2012.

13. Hu H, Krasinskas A and Willis J: Perspectives on current tumor-node-metastasis (TNM) staging of cancers of the colon and rectum. Semin Oncol 38: 500-510, 2011.

14. Bradford MM: A rapid and sensitive method for the quantitation of microgram quantities of protein utilizing the principle of protein-dye binding. Anal Biochem 72: 248-254, 1976.

15. Li B, Chen P, Chang Y, Qi J, Fu H and Guo H: Let-7a inhibits tumor cell growth and metastasis by directly targeting RTKN in human colon cancer. Biochem Biophys Res Commun 478: 739-745, 2016.

16. Majdalawieh A and Ro HS: PPARgamma1 and LXRalpha face a new regulator of macrophage cholesterol homeostasis and inflammatory responsiveness, AEBP1. Nucl Recept Signal 8: e004, 2010.

17. Holloway RW, Bogachev O, Bharadwaj AG, McCluskey GD, Majdalawieh AF, Zhang L and Ro HS: Stromal adipocyte enhancer-binding protein (AEBP1) promotes mammary epithelial cell hyperplasia via proinflammatory and hedgehog signaling. J Biol Chem 287: 39171-39181, 2012.

18. Yamashita S, Takahashi S, McDonell N, Watanabe N, Niwa T, Hosoya K, Tsujino Y, Shirai T and Ushijima T: Methylation silencing of transforming growth factor-beta receptor type II in rat prostate cancers. Cancer Res 68: 2112-2121, 2008. 
19. Sumpio C, Knobf MT and Jeon S: Treatment complexity: A description of chemotherapy and supportive care treatment visits in patients with advanced-stage cancer diagnoses. Support Care Cancer 24: 285-293, 2016.

20. Young JI, Mongoue-Tchokote S, Wieghard N, Mori M Vaccaro GM, Sheppard BC and Tsikitis VL: Treatment and survival of small-bowel adenocarcinoma in the United States: A comparison with colon cancer. Dis Colon Rectum 59: 306-315, 2016.

21. Muthalagu N, Junttila MR, Wiese KE, Wolf E, Morton J, Bauer B, Evan GI, Eilers $\mathrm{M}$ and Murphy DJ: BIM is the primary mediator of MYC-induced apoptosis in multiple solid tissues. Cell Rep 8: 1347-1353, 2014

22. Fang Y, Shen H, Li H, Cao Y, Qin R, Long L, Zhu X, Xie C and Xu W: miR-106a confers cisplatin resistance by regulating PTEN/Akt pathway in gastric cancer cells. Acta Biochim Biophys Sin (Shanghai) 45: 963-972, 2013.

23. Valeri N, Gasparini P, Braconi C, Paone A, Lovat F, Fabbri M, Sumani KM, Alder H, Amadori D, Patel T, et al: MicroRNA-21 induces resistance to 5 -fluorouracil by down-regulating human DNA MutS homolog 2 (hMSH2). Proc Natl Acad Sci USA 107: 21098-21103, 2010.
24. Mishra PJ,Humeniuk R, Mishra PJ,Longo-Sorbello GS, Banerjee D and Bertino JR: A miR-24 microRNA binding-site polymorphism in dihydrofolate reductase gene leads to methotrexate resistance. Proc Natl Acad Sci USA 104: 13513-13518, 2007.

25. Qiang R, Wang F, Shi LY, Liu M, Chen S, Wan HY, Li YX, Li X, Gao SY, Sun BC and Tang H: Plexin-B1 is a target of miR-214 in cervical cancer and promotes the growth and invasion of $\mathrm{HeLa}$ cells. Int J Biochem Cell Biol 43: 632-641, 2011.

26. Yang Z, Chen S, Luan X, Li Y, Liu M, Li X, Liu T and Tang H: MicroRNA-214 is aberrantly expressed in cervical cancers and inhibits the growth of HeLa cells. IUBMB Life 61: 1075-1082, 2009.

(c) (i) () This work is licensed under a Creative Commons Attribution-NonCommercial-NoDerivatives 4.0 International (CC BY-NC-ND 4.0) License. 